\title{
Emily Keddell
}

\section{Substantiat
Decision-M
and Risk Prediction in Child Protection Systems}

In the last few years, predictive risk modelling has been suggested for use in the child welfare environment as an efficient means of targeting preventive resources and improving practitioner decision-making. First raised in the green paper on vulnerable children, then translated into the white paper on vulnerable children and the Children's Action Plan, and now part of the Child, Youth and Family review remit, this particular tool has provoked a barrage of opinions and wide-ranging analyses, concerning ethical implications, feasibility and data issues, possible uses and political consequences (Ministry of Social Development, $2011,2012)$. This has resulted in a flurry of media, academic

Emily Keddell is a Senior Lecturer in Social Work at the University of Otago. and policy debates, both here and internationally, and many reviews and related publications (Dare, 2013; Fluke and Wulczyn, 2013; Oakley, 2013; Blank et al., 2013; Keddell, 2015a, 2015b; Oak, 2015; Gillingham, 2015; de Haan and Connolly, 2014; Ministry of Social Development, 2014a; Pierse, 2014; Shlonsky, n.d.). While there are many aspects of the tool that require debate and analysis, this article focuses on one: its use of substantiation data as the outcome variable it attempts 
to predict. Substantiation decisions are discussed in the light of the international literature, with some comment on the implications for child welfare system design. As the substantiation decision is variable, and the population available to be substantiated is skewed and heterogeneous, there are considerable challenges to using substantiation as a proxy for child abuse incidence across the population. This challenges its use for prediction at the individual level. However, the research this article draws on highlights the need for policy directions that address needs and risks across the macro, community and family levels; and the need for more research on the causes of decision-making variability in the child welfare context.

\section{Big data and 'carving out' the targets of social policy}

The use of big data in social life is steadily growing. From the selection of professional sportspeople to the shaping of outcomes in schools and universities, the use of data derived from administrative and other everyday sources is positioned as a source of important secrets, and reflects a 'profound faith' in the objectivity assumed to accompany it (Beer, 2015). Amoore and Piotukh (2015) argue that in an age of big data the use of algorithms to cut out particular slices or combinations of the data is not only descriptive, it is constitutive of social life: decisions, meanings and truths are generated in such a way as to promote certain ideas about society and individuals, while leaving others invisible. Indeed, Amoore and Piotukh (2015, p.4) argue that

an image of interest is extracted from a whole, data analytics are instruments of perception: they carve out images; reduce heterogeneous objects to a homogeneous space; and stitch together qualitatively different things such that attributes can be rendered quantifiable. (Amoore and Piotukh, 2015, p.4).

In this manner, the technologies of data analytics are increasingly powerful mediators, and even governors, of social and political life, yet their assumed objectivity is always a view of life, one shaped by the choices of data types, algorithm functions and accompanying narrative logics.

Predictive risk modelling is an example of the use of big data to 'carve out' images of risk in a specific way that have a number of implications for policy and practice. What is driving this particular image, what heterogeneities are being homogenised, and what slippages are occurring in this process? What is foregrounded and what is invisible in this particular slice of the data pie? How does the result influence perceptions of child abuse and policy responses to it?

\section{Why try to predict?}

Predictive modelling is proposed as a way to risk-scale the population with regard to child abuse, with a view to understanding
A number of feasibility studies have been conducted to examine if predictive risk modelling is possible. The main outcome variable used is substantiation, although others were considered by the Ministry of Social Development and may be considered in the future. The first study took place in 2012 and involved the use of data from two main sources: benefit data and Child, Youth and Family data (Vaithianathan, 2012; Vaithianathan et al., 2013). Research into risk factors based on both administrative and purpose-gathered data, as well as the development of actuarial risk assessment tools, is nothing new (Putnam-Hornstein and Needell, 2011; Shlonsky and Wagner, 2005; Baird and Wagner, 2000). However, the use of administrative data to first develop a model, then use it to

\section{... understanding who is most at risk of notification and resulting legal interventions is an important issue.}

and providing better preventive services, an elusive goal of child protection systems across the Western world. Increasing notifications to formal services threaten to swamp stretched existing systems in most anglophone countries (Spratt, 2012; Lonne, Harries and Lantz, 2013). In this context, understanding who is most at risk of notification and resulting legal interventions is an important issue. For example, Spratt (2012) considers that the impact of multiple adverse events on the population referred to child protection services is crucial to understanding how to target preventive resources effectively. Here in New Zealand, prediction has been attempted via the collection and integration of data sets from multiple administrative sources. Developed via the use of algorithms to identify particular risk factors for a specific outcome, then using that information to identify others prospectively, predictive modelling is seen as having potential as a method of predicting the people for whom the cooccurrence of specific combinations of administrative risk factors puts them at increased risk of future child abuse. prospectively risk-score other children, is new: the original authors note that they could find no other use of predictive risk modelling in this way in any journals worldwide, across several languages (Vaithianathan, 2012).

Following the first study published in 2012 (Vaithianathan et al., 2012; Vaithianathan et al., 2013), an application was made to extend the data set to include health and other data - in other words, all births in addition to the Ministry of Social Development data on beneficiaries only - and a further running of the model was completed and reported (Wilson et al., 2015). This study included: births, deaths and marriages data (Department of Internal Affairs); benefit data for the child and other children in the family; Child, Youth and Family data for the child, other children in the family, and their parents or caregivers (relating to their own childhoods); Department of Corrections data on sentences served by parents; and Ministry of Health data on the mother, child and recently born siblings. The latter included administrative markers of transience, mental health 
of the mother, and sibling intentional injury hospitalisations (Wilson et al., 2015, p.510). However, all health data were eventually omitted from the model, surprisingly, 'as these were found to not improve predictive accuracy' (Ministry of Social Development unpublished observations, in Wilson et al., 2015, p.511). The second study proceeded with the additional data from births, deaths and marriages from 2000 to 2012 - that is, all births - and sentencing histories of parents. While 12 different algorithms were tested, the most successful one concluded that the three most significant predictors of substantiation were: length of time spent on a benefit; contact with Child, Youth and Family as a child; and the substantiation of other children in the family.
Three uses of the model are currently suggested: first, in early identification, to score every baby at birth and offer those at the greatest level of risk (in the first model, the top decile; in the second, the top $5 \%$ ) a preventive family-level service; second, as a way to 'triage' decisionmaking at the point of intake into Child, Youth and Family services; and finally, to use in determining neighbourhoodlevel service needs (Predictive Modelling Working Group, 2014). The use in early identification - that is, at birth - has been put aside at this time due to lack of 'sufficient certainty' that the significant risks are 'outweighed by the potential benefits' (ibid., p.6). These suggested uses have different implications and issues; however, all rest on the assumed ability of the model to identify particular people as

\section{Substantiation data as a reflection of incidence have long been criticised by researchers in the child protection field, including in relation to this study (Fluke, 2009).}

In terms of predictive accuracy, the percentages of accurate prediction in the Vaithianathan et al. study were: in the top risk decile, $48 \%$ accuracy at predicting their substantiation in the system after five years, and in the top two deciles $37 \%$ accuracy. $44 \%$ of the total substantiated abuse in the time period was found in these top two deciles. In the Wilson et al. (2015) study, the predictive accuracy dropped slightly compared to the Vaithianathan study: of those in the highest risk-scoring 5\%, 31.6\% had been substantiated by age five years, and $69 \%$ had not. In the top risk decile (10\%), this accuracy dropped further to just $25.5 \%$.

Several ongoing tests of the predictive risk model are under way: for example, as an aid to decision-making at the point of notification. However, currently, and much to the dismay of the original progenitor, it has not been implemented as a method of ranking all children at birth and offering preventive services based on that score (Vaithianathan and Adams, 2015). at high risk. But just who are these models identifying? And what is the model able to say about them? A closer examination of the outcome it predicts helps answer these questions.

\section{Substantiation and incidence: using the decision-making ecology}

When building predictive algorithms, an outcome variable must be selected. Ideally this should be a yes/no, or at least a welldefined, variable, and the process that results in that event 'understood with a high degree of individual accuracy' (Pierse, 2014, n.p.). Does a person have cancer, or don't they? Will a person die within five years, or not? For the predictive risk modelling study purposes, the outcome variable chosen was substantiation, meaning a decision that abuse has been investigated and found to have occurred. How accurately the substantiation decision represents true incidence is, therefore, crucial to the effectiveness of the model (Gillingham, 2015). If substantiation is not consistent, or does not represent incidence, then identifying an algorithm to predict it will produce a skewed vision, a warped 'carve' as to whom it identifies at each risk decile, as well as which covariates are the most influential predictors of it.

No proxy is perfect, and the study authors have acknowledged that there is bias in the data due to issues related to the notification population (those notified to Child, Youth and Family). Acknowledging the biases in the population notified, however, does not (and cannot) account for variability in substantiation decisionmaking practices, and the identification of data distance from actual incidence should have an impact on data use. That is, an acknowledgement of the distance between any given proxy and true incidence, combined with the malleable outcome it seeks to predict, should influence the use of that data. In this instance, the distance between the proxy, the outcome and the actual incidence is a further reason to not pursue attempts to identify individuals.

Substantiation data as a reflection of incidence have long been criticised by researchers in the child protection field, including in relation to this study (Fluke, 2009). The primary problem is that many cases go unnotified, while some populations are subject to hypersurveillance, so that even minor incidents of abuse are identified and reported in some groups. A related issue is that the notified population is diverse, with severe social problems often notified due more to a lack of other options for practitioners than to the incidence of direct child abuse (López et al., 2015; Trocmé et al., 2014). The conundrum facing practitioners and statisticians alike is that the true incidence of child abuse in any population is likely much higher, and more evenly spread across the economic spectrum, than those cases referred to child protection services, yet the vast majority of those referred to child protection services are screened out. (For example, in New Zealand the notifications last year were 146,657 , but substantiated findings were only 19,623 , $13 \%$ of those notified (Child, Youth and Family, 2015; López et al., 2015).

Pierse (2014) argues that as child abuse has complex risk factors, and is 
an ill-defined term which incorporates different types with differing causes, using substantiation is unlikely to identify the large amount of abuse that goes undetected, particularly in populations able to avoid detection. Therefore, it is likely to simply 'reaffirm existing knowledge or biases within the established CYFS framework and may encourage less observation of [some communities]' (Pierse, 2014, p.2). Other commentators have agreed, noting that far from the claims of it being more 'objective' than practitioner decision-making, using substantiation as an outcome variable is likely to reinforce whatever biases exist in the current system (Keddell, 2015b). Shlonksy, one of the more favourable reviewers of the model, notes similar concerns, stating that a major issue is that a 'prognostic tool perpetuates the current system' (Shlonsky, n.d., p.2).

Many factors affect the extent to which substantiation can be considered a true indication of actual abuse across the population. These include who is notified to Child, Youth and Family in the first place - that is, the population available to be substantiated - and the substantiation decision itself. Various factors contribute to both these points of population flow through the Child, Youth and Family system and, therefore, the data derived from that system (Office of the Chief Social Worker, 2014). For example, when considering the notification population, families who are subject to more surveillance by potential notifiers tend to be over-represented, particularly those involved in public welfare systems or the justice system, or those in contact with non-governmental organisations (Bradt et al., 2015). This tends to mean over-notification of those who are poor, and, within that group, of those overrepresented among the poor: ethnic minorities, single parents and women (Roberts, 2002).

International research suggests that ethnicity and poverty often affect notification patterns. For example, a study by Mumpower (2010) compared incidence data with those referred (notified) to child protection services in the United States. He found that black children were disproportionately represented in rates of referral, and had higher rates of false positives - that is, those referred but not substantiated. However, he could also show, through the incidence data, that there was a higher rate of false negatives for black children - those who were abused but not notified. The rate of true positives - those referred and then substantiated - is higher for black children, but this was attributed to their higher rate of notification, showing that notifications were less accurate for black children than for children from other racial groups, but also that their apparent higher rate of abuse in child protection statistics was partly attributable to their higher rates of notification. Unfortunately, we have no national incidence study with which to compare child protection data in this way in New Zealand. Cram et al. (2015) completed a comparison of Māori the various types of abuse, with varying trajectories, causes and consequences, as well as definitional problems within each category (Cradock, 2014). This makes a unified approach to identifying risk factors and prediction in general difficult, as they are not tied to a single outcome phenomenon (Munro, Taylor and Bradbury-Jones, 2014). For example, the notification population includes a large majority who have issues related to high needs that affect the general health and well-being of children, as well as a minority for whom the immediate safety of the child requires urgent intervention (Trocmé et al., 2014; Munro, 2010; Spratt, 2012).

Numbers in New Zealand bear this out, with the vast majority of notifications not substantiated despite high needs (as noted earlier, of 146,657 notifications in

\section{... the greater question of whether the over-representation of poorer people and ethnic minorities in child protection figures represents true differences in rates of abuse or a biased child protection system.}

children's rates of contact with the child protection system with other indexes of poor outcomes as a proxy to evaluate this question (Drake et al., 2009; Drake et al., 2011). They showed that child protection statistics and other proxies for risk did not necessarily follow a similar trajectory, but sensibly concluded that this is open to a range of interpretations, including the impact of colonial history, the types of preventive health services available to Māori, and differences in cultural values.

The over-representation of people subject to a wide range of social problems also draws attention to two issues: the heterogeneous nature of the notified population, and that the population referred to child protection services is primarily a high-needs population, rather than high-risk (although these often overlap). The heterogeneous nature of the notification population occurs because of
$2014,19,623$, or $13 \%$, were substantiated), and of those who are, the majority are for the more ambiguous emotional abuse or neglect, with a minority for physical and sexual abuse $(5,912$ of 19,623 , or 30\%) (Child, Youth and Family, 2015a). The diversity of this group means predictive models will struggle to identify meaningful risk factors, as those that in fact confer high risk for some types of abuse will be 'cancelled out' by those that confer high risk for another, leaving behind potentially spurious or unrelated risk factors, such as contact with administrative systems.

These studies alert us to the greater question of whether the overrepresentation of poorer people and ethnic minorities in child protection figures represents true differences in rates of abuse or a biased child protection system. This wider debate is characterised 
as the 'risk-bias' or 'risk-need' debate, and has produced an immense range of research into how variables of race and class interact within child protection systems around the world. Too vast to summarise here, this research provides clues about the relationships between these factors and substantiation decisions as well as actual incidence (Jonson-Reid et al., 2009; Dettlaff et al., 2011; Dettlaff et al., 2015; Cram et al., 2015; Drake, Lee and Jonson-Reid, 2009; Bywaters et al., 2014a, 2014b; Williams and Soydan, 2005; Stokes and Schmidt, 2011; Pelton, 2015; Fluke et al., 2010; Ards et al., 2003; Arruabarrena and De Paúl, 2012; Wells, Merritt and Briggs, 2009; Wulczyn et al., 2013; Slack, Lee and Berger, 2007; the case characteristics remain the same (Keddell, 2014; Britner and Mossler, 2002; Platt and Turney, 2014; Skivenes and Stenberg, 2013; Regehr et al., 2010; English et al., 2002). Child abuse, while easily identifiable at its extremes, has many of grey areas, with numerous types and lack of clarity related to the socially constructed nature of definitions which vary immensely across time and place (Munro, 2007; Cradock, 2004). Even Shlonsky, in a review of the predictive risk model, states that ' $[\mathrm{o}]$ ne of the concerns I have with all PRM's predicting maltreatment is that maltreatment has been (and continues to be) difficult to define as a behaviour' (Shlonsky, n.d., p.1) The social malleability of abuse definitions

\section{Using vignettes removes the impact of higher levels of exposure to child protection services of minority and poorer families, allowing a clearer focus on decision-making post entry.}

Font, Berger and Slack, 2012). What can reasonably be concluded is that while poverty, particularly, does increase the risk of abuse, due to the increased stressors on poorer parents (particularly if they are operating in resource-poor families and communities), this disproportionality is overstated in child protection system contact, and thus in the data generated from it. The increased contact of poorer people with referrers is an important aspect often glossed over in this debate: the increase in incidence among some populations can only be investigated if it is seen; therefore, increases in child protection statistics can be an effect of poverty despite the appropriateness of the referral to services, and even if the child protection system is not biased.

\section{Practitioner and organisation-specific influences on decision outcomes}

In addition to the influence of these broader macro drivers of notifications, substantiation decisions are subject to a range of practitioner, institutional and policy orientation factors, even when affects substantiation decisions, as forcing a range of behaviours and circumstances into the abuse/not abuse dichotomy is often difficult and uncertain in practice.

Substantiation decisions can also relate to pragmatic factors, such as resource availability, that are unrelated to the events or behaviours occurring within the family. Current child welfare decision-making research conceptualises this complex, socially influenced decisionmaking process as occurring within a nested 'ecology'. This approach, known as the decision-making ecology (DME) approach, proposes that decisions in child welfare are influenced by individual decision-maker, institutional, contextual and macro-level factors (Baumann et al., 2011; López et al., 2015). Some of those factors, as noted above, include the impact of deprivation, poverty, ethnicity and policy orientation at the macro level, but others include the impact of professional discipline, organisational feedback and cultures, local resources and practitioner education and values. Davidson-Arad and Benbenishty (2014), for example, found that social workers in their study, through a survey of their values, could be divided into proand anti-removal (from birth parents) groups. When faced with case vignettes, these value groupings predicted whether the social workers recommended substantiation, removal and length of time in care, regardless of other practitioner demographics.

Enosh and Bayer-Topilsky (2014), in an Israeli study, examined practitioner responses to a series of vignettes. In a factorial survey study they presented the same case, but where some case families had low, some ambiguous and some high levels of objective 'risk', some families were of low and some of high socioeconomic status, and families were from both the dominant and minority ethnic groups (a $3 \times 2 \times 2$ factor survey). Using vignettes removes the impact of higher levels of exposure to child protection services of minority and poorer families, allowing a clearer focus on decisionmaking post entry. The researchers then elicited information about practitioner risk assessments and decisions. When asked if they could recommend out-ofhome placement, no placements were recommended for the no-risk group; $12 \%$ of those in the ambiguous group and $56 \%$ of the high-risk cases were recommended for removal. Comparing the findings by socio-economic status, they found that recommendations for out-of-home placement for ambiguous risk cases were $20.4 \%$ for the low socio-economic group, compared to $3.3 \%$ for the moderateto-high socio-economic status cases. Surprisingly, even in the obviously highrisk group, $87 \%$ of low socio-economic status children were recommended for removal, versus $26 \%$ of children from higher-income groups. Gillingham (2015) notes that some children are substantiated for reasons other than even a broad definition of abuse, such as behavioural problems or lack of a caregiver. These are just a few of a vast range of studies examining the impact of practitioner variables, apart from an objective and consistent assessment of abuse, on decision outcomes related to individual decision-makers (Cross and Casanueva, 2008; Detlaff and Rivaux, 2011). 
In addition to individual decisionmaker factors, site-specific organisational variables within child protection services also make a difference to decision outcomes, including differing levels of outof-home care resources, organisational cultures, thresholds for entry to services or legal intervention (that require a decision of 'substantiation') and levels of available non-government services. Bywaters et al. (2014a, 2015) examined the relationship between deprivation and contact with the child protection system in the UK. Not only did they find the anecdotally expected outcome that contact with the child protection system exists across a social gradient, with poorer children overrepresented, but, via spatial modelling, were able to show that an 'inverse intervention' law exists, similarly to other health inequalities research (Bywaters et al., 2015). This 'law' was expressed in their study by the observation that poorer children in small neighbourhood areas that were surrounded by wealthier areas (local authorities) had vastly higher rates of contact with the child protection system than poorer children living in small neighbourhood areas that were surrounded by similarly deprived larger geographical areas. This suggests that thresholds, neighbourhood resources and practitioner attitudes may differ between neighbourhoods and produce differing notification and substantiation practices, even when deprivation itself remains constant.

In another example, Fluke et al. (2010) tested the influence of organisational factors on decisions, with a view to understanding the over-representation of aboriginal children in Canada in child protection statistics. They utilised the decision-making ecology approach and found, drawing on the national incidence study, which included characteristics of workers and organisations, that the proportion of aboriginal reports to particular site-specific organisations (ranging from 20\% to more than 50\%) was a key predictor of decisions. Those organisations with high proportions of aboriginal children were more likely to have high removal rates, even when family income and case worker bias were

Table 1: Rates of distinct children with substantiated findings of abuse over notifications of concern, 2010 and 2014

\begin{tabular}{lllll}
\hline Region & $2010(\%)$ & $2014(\%)$ & $\begin{array}{l}2010 \text { actual } \\
\text { subs/nots }\end{array}$ & $\begin{array}{l}2014 \text { actual } \\
\text { subs/nots }\end{array}$ \\
\hline Te Tai Tokerau & 42 & 36 & $985 / 2311$ & $977 / 2712$ \\
Counties/Manukau & 46 & 45 & $3577 / 7743$ & $3309 / 7391$ \\
$\begin{array}{l}\text { Midlands (Bay of Plenty } \\
\text { Central (lower North }\end{array}$ & 51 & 50 & $2458 / 4817$ & $2263 / 4544$ \\
$\begin{array}{l}\text { Island) } \\
\text { Greater Wellington }\end{array}$ & 31 & 30 & $701 / 2239$ & $707 / 2332$ \\
Canterbury & 33 & 35 & $1005 / 3013$ & $1065 / 2712$ \\
Southern & 26 & 26 & $1211 / 4584$ & $1247 / 4658$ \\
\hline
\end{tabular}

controlled for. They contend that this difference in decision outcomes related solely to the proportions of aboriginal children, suggesting differences in community supports available for aboriginal families in different areas.

Font and Maguire-Jack (2015) also explored agency and geographic factors, case worker attributes and family characteristics in a national survey of wellbeing sample in the United States. They found that substantiation was 'strongly influenced by agency factors, particularly constraints on service accessibility. Substantiation is less likely when agencies can provide services to unsubstantiated cases and when collaboration with other social institutions is high' (Font and Maguire-Jack, 2015, p.70).

Does this apply to New Zealand? Some clues from descriptive statistics

What do we know about substantiation in New Zealand? While there is no empirical research into decision-making processes and outcomes in the public domain, what is known is this: the substantiation rate as a percentage of notifications ranges widely depending on the office location, suggesting that substantiations may be as subject here to individual and contextual variables as elsewhere. This is highlighted in the predictive risk modelling studies. Of the 13 variables retained after stepwise criteria had been applied in the Wilson et al. study, the Child, Youth and Family site office ranked the fourth most predictive variable, after other children with care and protection history, length of time spent on benefit in the last five years, and caregiver with a care and protection history (Wilson et al., 2015). This dropped to fifth when the most predictive variables across all 16 tested models were considered (Ministry of Social Development, 2014b). The predictive power of the site office suggests differences between office rates of substantiation. While it could be argued that this relates to different levels of need, these variables were only retained if they met the stepwise selection criteria: that is, 'The significance stay level was set to $\mathrm{p}<0.02$, allowing variables to remain in the model only if their significance was less than $\mathrm{p}<0.02$ when the effect of other variables was controlled' (Wilson et al., 2015, p.511). One could expect that if the predictive power of a site office reflected real differences in risk, then it would not be retained once other markers of need or risk had been controlled for. This suggests that it is something about site offices in and of themselves that is influential in substantiation outcomes.

Other clues can be found in descriptive statistics. An examination of substantiation figures shows that in the last year notifications (coming from referrers external to Child, Youth and Family) have remained stable. However, once notifications have entered the Child, Youth and Family system, numbers have dropped at every decision point, flowing through to a significant drop in emotional abuse and neglect substantiations, while other abuse types remain constant (down from 7,992 to 6,326 for emotional abuse, and from 3,510 to 2,695 for neglect for the period of 1 July-31 March 2014 and 2015) (Child Youth and Family, 2015a, 2015b). This suggests that different criteria are being used to substantiate those most contentious and ambiguous categories of emotional abuse and 
neglect. A further investigation by region shows that the rates of those notifications judged as 'requiring further action' to substantiation varies markedly by region (from $26 \%$ to $51 \%$ ), but remains fairly stable within each region over time (Table 1).

This suggests that substantiation rates may be more influenced by within-region thresholds and practices than by objective similarities between cases. A finer-grained analysis of site offices shows even more diversity of rates of substantiation and notifications, especially when compared to the total child populations covered by site offices. For example, in Clendon in $2014,9.4 \%$ of the total child population of 13,263 were notified to Child, Youth and Family, and of these, $37.6 \%$ were substantiated, representing $3.6 \%$ of the total child population. In Ōtara, $4.7 \%$ of have nothing to do with child or parent characteristics.' Thus, both our own divergent rates and international research suggest that 'substantiation is not a clear indication of maltreatment occurring or even the severity of maltreatment risks' (Shlonsky and Wagner, 2005, pp.415, 80).

\section{Understanding previous substantiations}

Finally, the data used in the predictive risk model administrative data set is not purpose-gathered and thus directly informed by international research into known risk factors, such as substance abuse, self-reported parental own experience of abuse, or poor mental health (although the Wilson et al. study did, sensibly, attempt to include a proxy for the latter from the benefit data). One effect of this is that certain variables become 'ghost variables': that is, their correlation

\section{... a model built to predict substantiation must be viewed somewhat cautiously as a particular 'carve' of the data which may construct an overlapping, uncertain subset of incidence.}

the total child population were notified, and $45.3 \%$ of those were substantiated, representing $2.1 \%$ of the total child population. In Wairoa, $11.3 \%$ of the child population were notified, but only $18 \%$ of these notifications were substantiated; this was $2 \%$ of the total child population. Substantiation rates as a percentage of notifications ranges from $16.2 \%$ in Timaru to $54.1 \%$ in Taumarunui (Child, Youth and Family, 2014; Ministry of Social Development, personal communication, 2015). These extremely divergent rates of substantiation suggest that factors other than objective similarities at different threshold points are driving substantiation decisions. Shlonsky and Wagner (2005) note that the data relied on to develop risk assessment models can be somewhat 'noisy' or variable, noting specifically that: 'For example, substantiation may be influenced by structural or institutional factors that with the outcome assumes a prominence despite its lack of explanatory or causative power.

For example, while previous substantiations were identified as a major predictive variable, subsequent substantiations of the same child or family cannot be considered as statistically comparable to previous substantiations for several reasons. First, flags exist in the Child, Youth and Family system already that alert Child, Youth and Family to new babies born to mothers who have previously had children removed or substantiated, and to the release into the community of offenders with convictions for violence against or abuse of children. Pregnant women with previous children removed, or who were children in care themselves, or who have convictions for offences against children will be monitored by Child, Youth and Family and are likely to have new babies 'substantiated' if removal at birth is required. This will be counted as a new substantiation, and in the data will suggest a correlation between the first and subsequent substantiations, yet its occurrence cannot be considered as separate from the earlier substantiation when compared to families with no previous contact with the Child, Youth and Family system. This may seem obvious, but what it means is that abuse occurring in families not monitored to the same degree as those already known to Child, Youth and Family will result in the predictive power of earlier substantiations assuming a statistical weighting not proportionate to the probable actual relationship with future substantiations. This may be further complicated by access to services generated by earlier substantiations (Jonson-Reid et al., 2010; Fuller and Nieto, 2014).

A history of substantiation is also likely to influence current decisions to substantiate for two other reasons, one clinical and one social. Chronicity is an aspect of many clinical definitions of child abuse, so the knowledge of past substantiations may help to form a 'chronic' picture in regard to the current notification, making re-substantiation more likely. Secondly, prior substantiation may also make practitioners more risk averse, as it is likely to heighten perceptions of future risk to the child, as well as of the practitioner's own liability, and lead to a substantiation decision being made (López et al., 2015). For these reasons the identification of earlier substantiation as a predictive variable should be treated with caution, as it is likely to over-identify those with previous substantiations, while not identifying others for whom abuse is occurring. This process is likely to reinforce other aspects of 'ratcheting' already in the system: that is, continuing to over-identify certain populations while lowering the portrayed risk of others (Harcourt, 2006). Over time this produces a distortive effect.

\section{Implications for systems design and social} work practice

Clearly, many complex factors influence the decision to substantiate, and the 
population notified to child protection services. Together, these patterns result in difficulties when using substantiation data to represent incidence for the purposes of developing individual risk prediction tools. Thus, a model built to predict substantiation must be viewed somewhat cautiously as a particular 'carve' of the data which may construct an overlapping, uncertain subset of incidence. Of course, all studies use various proxies and imperfect variables to 'stand in' for others. However, the rather extreme issues to do with substantiation in the child welfare context require particularly tentative interpretation, especially when the model is used not simply to describe the risk factors associated with substantiation, but to prospectively predict individuals who may abuse in the future. This sets predictive modelling in this special context apart from predictive models built to predict other types of outcomes. The lack of certainty in regard to substantiation decisions, the socially malleable nature of child abuse and its multiple types all limit its usefulness as a predictive tool - that is, as a way to identify specific individuals, whether for the allocation of preventive services or as an aid in child protection decision-making. In terms of social work practice, statistical predictive variables can assist in practitioner decision-making (via actuarial tools), but need to reflect actual incidence, and should be used in conjunction with a current practitioner assessment of risk (Shlonsky, n.d.; Shlonsky and Wagner, 2005; Munro, 2010; De Bortoli and Dolan, 2014; Platt and Turney, 2014).

Several researchers note the tendency for individualised risk scores to be utilised in negative ways in practice, where actuarial approaches are prioritised over professional judgement. While statistical modellers may understand the tentative nature of statistical prediction or correlation (that is, that just because someone has a heightened risk of a poor outcome, this does not predetermine them to experiencing it), practitioners tend to treat statistical data, especially when stripped of its explanatory variables, as solid knowledge, which can function as a received truth (Keddell, 2015a; Macdonald and Macdonald, 2010;
Stevens and Hassett, 2012). The reification of risk scores has implications both for those deemed at high risk - interventions may be more intrusive than warranted and for those deemed at low risk, who may be passed over for intervention due to a low risk score, when actual family functioning may be extremely abusive. The use of actuarially derived risk scores can also draw practitioners away from considering children and families as existing in 'complex adaptive systems that must be considered when looking to assess risk in such cases' (Stevens and Hassett, 2012, p.503), particularly in risk-averse environments increasingly driven by fear of personal liability if a high risk status is viewed as not having been properly 'acted on' (Kemshall, 2010; Fleming et al., 2014; Broadhurst et al., 2010). On the other hand, professional judgement can only be properly considered in the real-world contexts in which it may be used, and the development issues to do with substantiation discussed above add heightened caution to its use in practice.

In terms of system design, the current use of the same data set by Treasury may provide a more useful approach that links high-risk groups (of a range of poor outcomes) to areas of high need and multiple risk factors across a community (Crichton, Templeton and Tumen, 2015). A community-level use of the predictive risk model has been suggested, and was also preferred by prominent reviewers. For example, in the Fluke review, Fluke states in response to the suggested use to target preventive services:

We believe these resources should be prioritised geographically, consistent

\section{Interventions currently available for this high-risk group are limited. They require tertiary, tailored services able to work with families intensively and supportively, not simply child removal.}

alone is far from perfect. It can be subject to errors of bias and a sometimes unhelpful reliance on heuristics or rules of thumb, particularly in situations of low validity, time pressure, poor feedback and uncertain outcomes, all intrinsic to the child protection environment (Kahneman, 2011; Munro, 2011). In some studies professional judgement performs no better than chance at predicting future risk (van der Put et al., 2016). Many developments in decisionmaking include aspects of both actuarial and professional judgement in the use of decision-making tools (de Bartoli, 2014; Shlonsky and Wagner, 2005). To some extent, the practice issues associated with predictive risk modelling may be considered implementation issues, and the use of risk scores here was proposed as an aid to professional judgement (rather than to supplant it). However, the value of a predictive risk model with areas where there are more children at risk. Obviously, the approach we are recommending would focus more on populationbased resource allocations compared to individual allocations in the form of referrals ... what is really unclear and troubling is whether the MSD has services that will ameliorate the risk - in other words, if they refer children and the services don't work - because the services are ineffective - and the family 'fails' ... to what extent will that then form the basis for a more deep end service like removal? (Fluke and Wulczyn, 2013, p.7)

Shlonsky also recommends a community-level provision of services, suggesting that there may be 'geographic areas of disadvantage that can be better resourced' (Shlonsky, n.d., p.2). The 
third currently proposed use of the tool is therefore more likely to offer the best response, in a manner commensurate with the limited ability of the tool to identify individual risks accurately.

Another issue for child welfare system design highlighted by this article is that diversity within the notified and substantiated populations calls for different service approaches. It is likely that the population identified by the predictive risk model are already known to services, as the top variables relate to contact with the Child, Youth and Family system (although this would have been worth investigating properly in the now-cancelled prospective study, where children were to be risk-scored at birth, then followed to see if they would gain access to services anyway) (Ministry of Social Development, 2014b). If this is the case, then the problem is not of identification, but how we respond to high-risk families. Interventions currently available for this high-risk group are limited. They require tertiary, tailored services able to work with families intensively and supportively, not simply child removal. When people who have been in care become parents, for example, particular supports are required. As noted above, the broader notified population is a diverse one and tends to be a highneeds group. This wider group requires much better access to universal social protections such as poverty reduction and adequate housing, more 'hooded' targeted family support services (those connected to universal services), and community need-based levels of mental health, substance abuse and domestic violence services. As Pierse notes, the real problem is that we need 'more resources and more interventions' rather than better ways to identify risky individuals (Pierce, 2014, n.p.; Unicef, 2003; Sethi et al., 2015; Spratt et al., 2014). The Ministry of Social Development has also noted this issue, recommending deferral of the use of predictive risk modelling in early identification until 'there is capacity to respond appropriately to the children referred' (Predictive Modelling Working Group, 2014, pp.6-7). Finally, better decision-making research into how substantiations are generated in New Zealand is needed, in order to understand the processes leading to variability in decision outcomes across complex interactions between macro, institutional and individual factors.

\section{References}

Amoore, L. and V. Piotukh (2015) 'Life beyond big data: governing with little analytics', Economy and Society, pp.1-26

Ards, S.D., S.L. Myers, C. Chung, A. Malkis and B. Hagerty (2003) 'Decomposing black-white differences in child maltreatment', Child Maltreatment, 8 (2), pp.112-21

Arruabarrena, I. and J. De Paúl (2012) 'Improving accuracy and consistency in child maltreatment severity assessment in child protection services in Spain: new set of criteria to help caseworkers in substantiation decisions', Children and Youth Services Review, 34 (4), pp.666-74

Baird, C. and D. Wagner (2000) 'The relative validity of actuarial and consensus-based risk assessment systems', Children and Youth Services Review, 22 (11/12), pp.839-71

Baumann, D.J., L. Dalgleish, J. Fluke and H. Kern (2011) The DecisionMaking Ecology, Washington, DC: American Humane Association

Beer, D. (2015) 'Productive measures: culture and measurement in the context of everyday neoliberalism', Big Data and Society, 2 (1), pp.112

Blank, A., F. Cram, T. Dare, I. De Haan, B. Smith and R. Vaithianathan (2013) 'Ethical issues for Māori in predictive risk modelling to identify new-born children who are at high risk of future maltreatment', Wellington: Ministry of Social Development

Bradt, L., G. Roets, R. Roose, Y. Rosseel and M. Bouverne-De Bie (2015) 'Poverty and decision making in child welfare and protection: deepening the bias-need debate', British Journal of Social Work, 45 (7), pp.2161-75

Britner, P.A. and D.G. Mossler (2002) 'Professionals' decision-making about out-of-home placements following instances of child abuse', Child Abuse and Neglect, 26 (4), pp.317-32

Broadhurst, K., C. Hall, D. Wastell, S. White and A. Pithouse (2010) 'Risk, instrumentalism and the humane project in social work: identifying the informal logics of risk management in children's

statutory services', British Journal of Social Work, 40 (4), pp.104664

Bywaters, P., G. Brady, T. Sparks and E. Bos (2014a) 'Child welfare inequalities: new evidence, further questions', Child and Family Social Work, pp.1-12

Bywaters, P., G. Brady, T. Sparks and E. Bos (2014b) Deprivation and Inequalities in Children's Services: research briefing paper 1, Coventry: Coventry University

Bywaters, P., G. Brady, T. Sparks, E. Bos, L. Bunting, B. Daniel, B. Featherstone, K. Morris and J. Scourfield (2015) 'Exploring inequities in child welfare and child protection services: explaining the "inverse intervention law"', Children and Youth Services Review, 57, pp.98105

Child, Youth and Family (2015a) 'Key statistics and information for media', http://www.cyf.govt.nz/about-us/who-we-are-what-we-do/ information-for-media-backup.html, accessed 8 August 2014

Child, Youth and Family (2015b) Personal communication: rates of substantiation and population denominators

Cradock, G. (2004) 'Risk, morality and child protection: risk calculation as guides to practice', Science Technology Human Values, 29 (3), pp.314-31

Cradock, G. (2014) 'Who owns child abuse?', Social Sciences, 3 (4), pp. $854-70$

Cram, F., P. Gulliver, R. Ota and M. Wilson (2015) 'Understanding overrepresentation of indigenous children in child welfare data: an application of the drake risk and bias models', Child Maltreatment, 20 (3), pp.170-82

Crichton, S., R. Templeton and S. Tumen (2015) 'Using integrated administrative data to understand children at risk of poor outcomes as young adults', Wellington: Treasury

Cross, T.P. and C. Casanueva (2008) 'Caseworker judgements and substantiation', Child Maltreatment, 20 (10), pp.1-15 
Dare, T. (2013) 'Predictive risk modelling and child maltreatment: ethical challenges', Children in Crisis, Hamilton: University of Waikato

Davidson-Arad, B. and R. Benbenishty (2014) 'Child welfare attitudes, risk assessments and intervention recommendations: the role of professional expertise', British Journal of Social Work, doi:10.1093/ bjsw/bcu110

De Haan, I. and M. Connolly (2014) 'Another Pandora's box? Some pros and cons of predictive risk modeling', Children and Youth Services Review, 47, part 1, pp.86-91

Detlaff, A. and S. Rivaux (2011) 'Disentangling substantiation: the influence of race, income, and risk on the substantiation decision in child welfare', Children and Youth Services Review, 33 (9), pp.1630-7

Dettlaff, A.J., J. Christopher Graham, J. Holzman, D.J. Baumann and J.D. Fluke (2015) 'Development of an instrument to understand the child protective services decision-making process, with a focus on placement decisions', Child Abuse \& Neglect, doi: 10.1016/j. chiabu.2015.04.007

Dettlaff, A.J., S.L. Rivaux, D.J. Baumann, J.D. Fluke, J.R. Rycraft and J. James (2011) 'Disentangling substantiation: the influence of race, income, and risk on the substantiation decision in child welfare', Children and Youth Services Review, 33 (9), pp.1630-7

Drake, B., J.M. Jolley, P. Lanier, J. Fluke, R.P. Barth and M. Jonson-Reid (2011) 'Racial bias in child protection? A comparison of competing explanations using national data', Pediatrics, 127, pp.471-8

Drake, B., S.M. Lee and M. Jonson-Reid (2009) 'Race and child maltreatment reporting: are blacks overrepresented?', Children and Youth Services Review, 31 (3), pp.309-16

English, D., D. Marshall, L. Coglan, S. Brummel and M. Orme (2002) 'Causes and consequences of the substantiation decision in Washington Child Protective Services', Children and Youth Services Review, 24 (11), pp.817-51

Enosh, G. and T. Bayer-Topilsky (2014) 'Reasoning and bias: heuristics in safety assessment and placement decisions for children at risk', British Journal of Social Work, 45 (6), pp.1771-87

Fleming, P., L. Biggart and C. Beckett (2014) 'Effects of professional experience on child maltreatment risk assessments: a comparison of students and qualified social workers', British Journal of Social Work, doi:10.1093/bjsw/bcu090

Fluke, J. (2009) 'Allegory of the cave: on the theme of substantiation', Child Maltreatment, 14 (1), pp.69-72

Fluke, J.D., M. Chabot, B. Fallon, B. Maclaurin and C. Blackstock (2010) 'Placement decisions and disparities among aboriginal groups: an application of the decision making ecology through multi-level analysis', Child Abuse and Neglect, 34 (1), pp.57-69

Fluke, J.D. and F. Wulczyn (2013) 'Peer and statistical review of the report: "Final report on the feasibility of using predictive modelling to identify new-born children who are at high risk of future maltreatment" and the "companion technical report"', Wellington: Ministry of Social Development

Font, S.A., L.M. Berger and K.S. Slack (2012) 'Examining racial disproportionality in Child Protective Services case decisions', Children and Youth Services Review, 34 (11), pp.2188-200

Font, S.A. and K. Maguire-Jack (2015) 'Decision-making in child protective services: influences at multiple levels of the social ecology', Child Abuse and Neglect, 47, pp.70-82
Fuller, T. and M. Nieto (2014) 'Child welfare services and risk of child maltreatment rereports: do services ameliorate initial risk?', Children and Youth Services Review, 47, part 1, pp.46-54

Gillingham, P. (2015) 'Predictive risk modelling to prevent child maltreatment and other adverse outcomes for service users: inside the "black box" of machine learning', British Journal of Social Work, doi:10.1093/bjsw/bcv031

Harcourt, B.E. (2006) Against Prediction: profiling, policing, and punishing in an actuarial age, Chicago: University of Chicago Press

Jonson-Reid, M., B. Drake and P.L. Kohl (2009) 'Is the overrepresentation of the poor in child welfare caseloads due to bias or need?', Children and Youth Services Review, 31 (3), pp.422 -7

Jonson-Reid, M., C.R. Emery, B. Drake and M.J. Stahlschmidt (2010) 'Understanding chronically reported families', Child Maltreatment, 15 (4), pp.271-81

Keddell, E. (2014) 'Current debates on variability in child welfare decision-making: a selected literature review', Social Sciences, 3 (1) (special issue: Developments in Child Protection), pp.916-40, doi:10.3390/socsci3040916

Keddell, E. (2015a) 'The ethics of predictive risk modelling in the Aotearoa/New Zealand child welfare context: child abuse prevention or neo-liberal toot?', Critical Social Policy, 35 (1), pp.69-88

Keddell, E. (2015b) 'Predictive risk modelling: on data, rights and politics', blog post at Reimagining Social Work in Aotearoa New Zealand, 4 June, http://www.reimaginingsocialwork.nz/2015/06/ predictive-risk-modelling-on-rights-data-and-politics/

Kemshall, H. (2010) 'Risk rationalities in contemporary social work practice', British Journal of Social Work, 40, pp.1247-62

Lonne, B., M. Harries and S. Lantz (2013) 'Workforce development: a pathway to reforming child protection systems in Australia', British Journal of Social Work, 43 (8), pp.1630-48

López, M., J.D. Fluke, R. Benbenishty and E.J. Knorth (2015) 'Commentary on decision-making and judgments in child maltreatment prevention and response: an overview', Child Abuse and Neglect, 49, pp.1-11

Macdonald, G. and K. Macdonald (2010) 'Safeguarding: a case for intelligent risk management', British Journal of Social Work, 40, pp.1174-91

Ministry of Social Development (2011) Every Child Thrives, Belongs, Achieves, green paper on vulnerable children, Wellington: New Zeland Government

Ministry of Social Development (2012) Children's Action Plan: identifying, supporting and protecting vulnerable children, white paper for vulnerable children, Wellington: New Zealand Government

Ministry of Social Development (2014a) 'Consultation paper: children's action plan approved information sharing agreement', Wellington: Minsitry of Social Development

Ministry of Social Development (2014b) 'The feasibility of using predictve risk modelling to identify new-born children who are high priority for preventive services: final report', Wellington: Ministry of Social Development

Mumpower, J.L. (2010) "Disproportionality at the "front end" of the child welfare services system: an analysis of rates of referrals, "hits", "misses", and "false alarms", Journal of Health and Human Services Administration, 33 (3), pp.364-405

Munro, E. (2007) Child Protection, London: Sage 
Munro, E. (2010) 'Conflating risks: implications for accurate risk prediction in child welfare services', Health, Risk and Society, 12 (2), pp. $119-30$

Munro, E., J. Taylor and C. Bradbury-Jones (2014) 'Understanding the causal pathways to child maltreatment: implications for health and social care policy and practice', Child Abuse Review, 23 (1), pp.6174

Oak, E. (2015) 'A minority report for social work? The predictive risk model (PRM) and the Tuituia assessment framework in addressing the needs of New Zealand's vulnerable children', British Journal of Social Work, doi:10.1093/bjsw/bcv028

Oakley, J. (2013) 'Referee report on "Predictive Risk Modelling and Child Maltreatment: an ethical review"', Wellington: Ministry of Social Development

Office of the Chief Social Worker (2014) 'Workload and casework review: qualitative review of social worker caseload, casework and workload management', Wellington: Child, Youth and Family

Pelton, L.H. (2015) 'The continuing role of material factors in child maltreatment and placement', Child Abuse and Neglect, 41, pp.30-9

Pierse, N. (2014) 'Scientific review of predictive risk modelling', Wellington: Health and Disability Ethics Committee

Platt, D. and D. Turney (2014) 'Making threshold decisions in child protection: a conceptual analysis', British Journal of Social Work, 44 (6), pp.1472-90

Predictive Modelling Working Group (2014) 'Vulnerable children predictive modelling: design for testing and trialling', Cabinet briefing paper, Ministry of Social Development, 7 November

Putnam-Hornstein, E. and B. Needell (2011) 'Predictors of child protective service contact between birth and age five: an examination of California's 2002 birth cohort', Children and Youth Services Review, 33 (8), pp.1337-44

Regehr, C., M. Bogo, A. Shlonsky and V. Leblanc (2010) 'Confidence and professional judgment in assessing children's risk of abuse', Research on Social Work Practice, 20 (6), pp.621-8

Roberts, D. (2002) Shattered Bonds: the color of child welfare, New York: Basic Civitas Books

Sethi, D., M. Bellis, K. Highes, R. Gilbert, F. Mitis and G. Galea (2015) European Report on Preventing Maltreatment, Copenhagen: World Health Organisation

Shlonsky, A. (n.d.) 'Expert review: predictive modeling: design for an initial phase of testing and trialing', Wellington: Ministry of Social Development

Shlonsky, A. and D. Wagner (2005) 'The next step: integrating actuarial risk assessment and clinical judgment into an evidence-based practice framework in CPS case management', Children and Youth Services Review, 27, pp.409-27

Skivenes, M. and H. Stenberg (2013) 'Risk assessment and domestic violence: how do child welfare workers in three countries assess and substantiate the risk level of a 5-year-old girl?', Child and Family Social Work, 20 (4) pp.424-36
Slack, K.S., B. Lee and L. Berger (2007) 'Do welfare sanctions increase child protection system involvement? A cautious answer', Social Service Review, 81 (2), pp.207-28

Spratt, T. (2012) 'Why multiples matter: reconceptualising the population referred to child and family social workers', British Journal of Social Work, 42 (8) pp.1574-91

Spratt, T., J. Nett, L. Bromfield, J. Hietamäki, H. Kindler and L. Ponnert (2014) 'Child protection in Europe: development of an international cross-comparison model to inform national policies and practices', British Journal of Social Work, 45 (5), pp.1508-25

Stevens, I. and P. Hassett (2012) 'Non-linear perspectives of risk in social care: using complexity theory and social geography to move the focus from individual pathology to the complex human environment', European Journal of Social Work, 15 (4), pp.503-13

Stokes, J. and G. Schmidt (2011) 'Race, poverty and child protection decison making', Brisith Journal of Social Work, 41, pp.1105-21

Trocmé, N., A. Kyte, V. Sinha and B. Fallon (2014) 'Urgent protection versus chronic need: clarifying the dual mandate of child welfare services across Canada', Social Sciences, 3 (3), pp.483-98

Unicef (2003) 'A league table of child maltreatment deaths in rich nations', Innocenti Report Card, 5, Florence: Innocenti Research Centre

Vaithianathan, R. (2012) Can Administrative Data Be Used to Identify Children at Risk of Adverse Outcomes?, Auckland: Business School, Department of Economics, University of Auckland

Vaithianathan, R. and D. Adams (2015) Interview with Rhema Vaithianathan, Auckland Univeristy of Technology, and Dorothy Adams, general manager of insights, Ministry of Social Development, Radio New Zealand Morning Report, 12 May

Vaithianathan, R., T. Maloney, E. Putnam-Hornstein and N. Jiang (2013) 'Children in the public benefit system at risk of maltreatment: identification via predictive modeling', American Journal of Preventive Medicine, 45 (3), pp.354-9

van der Put, C.E., M. Assink and G.J.J.M. Stams (2016) 'Predicting relapse of problematic child-rearing situations', Children and Youth Services Review, 61, pp.288-95

Wells, S.J., L.M. Merritt and H.E. Briggs (2009) 'Bias, racism and evidence-based practice: the case for more focused development of the child welfare evidence base', Children and Youth Services Review, 31 (11), pp.1160-71

Williams, C. and H. Soydan (2005) 'When and how does ethnicity matter? A cross-national study of social work responses to ethnicity in child protection cases', British Journal of Social Work, 35 (6), pp.901-20

Wilson, M.L., S. Tumen, R. Ota and A.G. Simmers (2015) 'Predictive modeling: potential application in prevention services', American Journal of Preventive Medicine, 48 (5), pp.509-19

Wulczyn, F., R. Gibbons, L. Snowden and B. Lery (2013) 'Poverty, social disadvantage, and the black/white placement gap', Children and Youth Services Review, 35 (1), pp.65-74 